Acta Crystallographica Section D

Biological Crystallography

ISSN 0907-4449

\title{
Purification, crystallization and Patterson search of haemoglobin IV from the armoured catfish Liposarcus anisitsi
}

Considerable interest is currently focused on fish haemoglobins in order to identify the structural basis for their diversity of functional behaviour. The armored catfish Liposarcus anisitsi presents accessorial air breathing through a modified stomach, which allows this species to survive in waters with low oxygen content. The analysis of its haemolysate has shown the presence of four main haemoglobins, with this work focusing on haemoglobin IV (LaHb-IV). LaHb-IV was crystallized and X-ray diffraction data were collected to $2.4 \AA$ resolution using a synchrotron-radiation source. The crystal belongs to the orthorhombic space group $P 2_{1} 2_{1} 2_{1}$, with unit-cell parameters $a=52.6(1), b=104.8(2), c=113.9$ (2) §; preliminary structural analysis revealed the presence of one tetramer in the asymmetric unit. The structure was determined using the standard molecularreplacement technique.
Received 1 September 1999 Accepted 17 July 2001
${ }^{a}$ Departamento de Física, Instituto de Biociências, Letras e Ciências Exatas, UNESP, São José do Rio Preto, SP 15054-000, Brazil ${ }^{\text {b}}$ Centro Universitário de Votuporanga, Votuporanga, SP 15500-030, Brazil, 'Centro Universitário Moacyr Sreder Bastos, CEP 23050-290, Rio de Janeiro, RJ, Brazil, dDepartamento de Física, Faciba-FEB, Barretos, SP 14783-226, Brazil, êDepartamento de Química e Geociências, Instituto de Biociências, Letras e Ciências Exatas, UNESP, São José do Rio Preto, SP 15054-000, Brazil, and ${ }^{\mathrm{f} C}$ Center for Applied Toxinology-CEPIDFAPESP, Av. Vital Brasil 1500, São Paulo, SP 05503-900, Brazil

Correspondence e-mail: walterfa@df.ibilce.unesp.br
(C) 2001 International Union of Crystallography Printed in Denmark - all rights reserved

\section{Introduction}

Fish haemoglobins exhibit a greater variety of functional behaviour compared with mammalian haemoglobins, in terms of cooperative ligand binding and allosteric control exerted by a variety of chemical factors, such as $\mathrm{H}^{+}$, $\mathrm{Cl}^{-}, \mathrm{CO}_{2}$ and 2,3-biphosphoglycerate (BPG) (DeYoung et al., 1994). This characteristic reflects a structural diversity guided by evolutionary pressure exerted by the adaptation to differing environmental and physiological needs (Perutz, 1996; DeYoung et al., 1994; Fadel et al., 2000; Smarra et al., 1997, 1999, 2000).

Vertebrate haemoglobins cooperatively bind molecular oxygen, the required electron acceptor in the respiratory chain. Several chemical agents, known as heterotropic ligands, and also temperature can influence haemoglobin oxygen equilibria (Perutz, 1996; Seixas et al., 1999). For most vertebrate haemoglobins, oxygen affinity at alkaline $\mathrm{pH}$ is lowered, a property known as the Bohr effect. This property arises from preferential proton binding to the low $\mathrm{O}_{2}$-affinity state (T) and its stabilization (Perutz, 1996; Camardella et al., 1992). An exaggerated response to proton binding is present in several fish haemoglobins and is known as the Root effect, with a presumed role in pumping oxygen into the fishes' swim bladders (Brittain, 1987; Honda et al., 2000)

On oxygenation, human haemoglobin liberates one proton per tetramer, whereas carp haemoglobin liberates 3.6 protons per tetramer. Based on the high-resolution crystallographic structure of the carbon monoxide bound form of haemoglobin from Leiostomus xanthurus, Mylvaganam et al. (1996) proposed a molecular mechanism for the Root effect. The authors proposed that positively charged clusters across the $\beta 1-\beta 2$ interface in the R-state, identified in the structure, are responsible for part of the Root effect. When $\mathrm{pH}$ lowers, protonation of the $\beta \mathrm{N}$-terminus and His $\beta 147(\mathrm{HC} 3)$ within these clusters is claimed to destabilize the R-state and to promote the acid-triggered allosteric $\mathrm{R} \rightarrow \mathrm{T}$ transition, with concomitant $\mathrm{O}_{2}$ release. More recently, a new fish haemoglobin structure became available (Mazzarella et al., 1999) and its structural analysis led to somewhat contrasting results with the above explanation of the Root effect, suggesting that the differences in the $\mathrm{pH}$ dependence cannot be related to the modulation of the R-state as had been proposed previously.

L. anisitsi (Siluriformes, Loricariidae) is a South American armoured catfish able to survive in waters with very low oxygen content owing to its ability to gulp air at the surface. The modified stomach, which acts as an accessorial gas-exchange organ, permits more efficient blood oxygenation. Four haemoglobins have been identified in its haemolysate, with isoelectric points ranging from 7.2 to 8.3 (Smarra et al., 1997, 2000). The present work was performed on LaHb-IV.

\section{Materials and methods}

\subsection{Purification}

Blood was collected by caudal puncture after an adaptive period of $4 \mathrm{~d}$ in aquaria. 
Subsequent procedures were carried out at low temperature (around $277 \mathrm{~K}$ ). Red blood cells were washed by centrifugation four times with buffered saline $(50 \mathrm{~m} M$ Tris $\mathrm{pH}$ 8.5 containing $1 \mathrm{~m} M$ EDTA). Haemolysis was accomplished with buffer $A(50 \mathrm{~m} M$ Tris- $\mathrm{HCl}$ pH 8.5 containing $1 \mathrm{~m} M$ EDTA), followed by centrifugation ( $1000 \mathrm{~g}$ for $1 \mathrm{~h}$ ) and filtration to remove debris. An aliquot was kept for phosphate determination. For phosphate removal, haemolysate dialysis was performed against buffer $A$, followed by gel filtration on a $1.6 \times 70 \mathrm{~cm}$ column (Sephadex G-25).

Haemoglobin purification was performed on DEAE-Sephadex A-50 using a $\mathrm{pH}$ gradient between buffer $A$ and $50 \mathrm{~m} M$ bis-Tris $\mathrm{pH}$ 6.5. The isolated components were further deionized by several passages through a mixed-bed Amberlite MB-1 (Sigma), concentrated by centrifugation on Amicon microconcentrators and stored in liquid nitrogen until use. Four main haemoglobins were identified in the haemolysate: LaHb-I, LaHb-II, LaHb-III and LaHb-IV.

Non-denaturating electrophoresis was performed in $10 \%$ polyacrylamide gel and cellulose acetate.

Analytical isoelectric focusing was performed in agarose gels. The bands containing haemoglobin were cut off and eluted in deionized water for $\mathrm{pH}$ measurement and isoelectric point estimation.

\subsection{Crystallization and $X$-ray data collection}

The oxygenated form of LaHb-IV was concentrated to $10 \mathrm{mg} \mathrm{ml}^{-1}$ in $50 \mathrm{mM}$ Tris- $\mathrm{HCl} \mathrm{pH}$ 8.5.

Crystallization trials were performed using the hanging-drop vapour-diffusion method at a temperature of $298 \mathrm{~K}$.

Crystals of LaHb-IV were obtained in several different crystallization conditions using the hanging-drop vapour-diffusion and sparse-matrix methods (Jancarik \& Kim, 1991). The best crystals were obtained after $2 \mathrm{~d}$ growth from drops in which $7 \mu \mathrm{l}$ of haemoglobin solution $\left(10 \mathrm{mg} \mathrm{ml}^{-1}\right)$ was mixed with an equal volume of reservoir solution ( $0.1 \mathrm{M}$ Tris- $\mathrm{HCl} \mathrm{pH} \quad 8.5,0.2 \mathrm{M}$ sodium acetate, $30 \%$ PEG 4000$)$. The crystals were harvested in the well buffer and mounted in $1.0 \mathrm{~mm}$ borosilicate glass capillary tubes for X-ray data collection.

$\mathrm{X}$-ray diffraction data were collected from a single LaHb-IV crystal at a temperature of $281 \mathrm{~K}$ and a wavelength of $1.547 \AA$ using the Synchrotron Radiation Source [Station PCr, Laboratório Nacional de Luz Síncrotron
(LNLS), Campinas, Brazil; Polikarpov, Oliva et al., 1998; Polikarpov, Perles et al., 1998] and a $34.5 \mathrm{~cm}$ MAR imaging-plate detector (MAR Research) with an exposure time of 2 min per image. The crystal-to-detector distance was $150 \mathrm{~mm}$. Using an oscillation range of $0.8^{\circ}, 100$ images were collected. The raw X-ray diffraction data were processed to $2.4 \AA$ resolution using the program DENZO (Otwinowski, 1993) and scaled with the program SCALEPACK (Otwinowski, 1993). Autoindexing procedures combined with analysis of the X-ray diffraction pattern and averaging of equivalent intensities were used in the characterization of the Laue symmetry.

\subsection{Molecular replacement}

The crystal structure of LaHb-IV was determined by standard molecularreplacement methods using the program AMoRe (Navaza, 1994). The atomic coordinates of eight different fish haemoglobins and one human haemoglobin deposited in the PDB (Abola et al., 1997) were used as search models. All solvent molecules were removed from the search models; however, the haem groups were retained. The search models which presented more than one dimer were modified so that only one dimer $(\alpha \beta)$ was used in the molecular replacement. The atomic coordinates for all search models were translated so that their centre of gravity is at the origin; they were also rotated so that the principal axes of inertia of the search models are parallel to the orthogonal axes. The PDB codes of the search models are listed in Table 1. Crossrotation functions were calculated in the resolution range 10 $4.5 \AA$ using a sampling step of $2.5^{\circ}$ for all nine search models. These calculations were carried out with an integration radius of $22.5 \AA$. The rotation which generated the highest correlation coefficient (CC) was applied to the search models and used in the subsequent translationfunction computations, based on data in the same resolution range.

The best solutions for each search model were selected based on the magnitude of the $R_{\text {factor }}$ and correlation coefficient. Translation functions for space groups $P 222, P 2_{1} 2_{1} 2$ and $P 222_{1}$ have also been computed using the same resolution range
Table 1

List of the haemoglobins used as search models for molecular replacement.

\begin{tabular}{|c|c|}
\hline PDB code & Protein \\
\hline 1hho & $\begin{array}{l}\text { Oxy haemoglobin from } \\
\text { Homo sapiens }\end{array}$ \\
\hline $1 \mathrm{t} 1 \mathrm{n}$ & $\begin{array}{l}\text { Carbonmonoxy haemoglobin from } \\
\text { the fish Trematomus akajei }\end{array}$ \\
\hline 1ouu & $\begin{array}{l}\text { Carbonmonoxy haemoglobin from } \\
\text { the fish Oncorhyncus mykiss }\end{array}$ \\
\hline $1 \operatorname{cg} 8$ & $\begin{array}{l}\text { Carbonmonoxy haemoglobin from } \\
\text { the fish Dasyatis akajei }\end{array}$ \\
\hline 1hbh & $\begin{array}{l}\text { Deoxy haemoglobin from } \\
\text { the fish Pagothenia bernacchii }\end{array}$ \\
\hline 1out & $\begin{array}{l}\text { Deoxy haemoglobin from } \\
\text { the fish } O . \text { mykiss }\end{array}$ \\
\hline $1 \mathrm{pbx}$ & $\begin{array}{l}\text { Carbonmonoxy haemoglobin from } \\
\text { the fish Pagothenia bernacchii }\end{array}$ \\
\hline $1 \mathrm{spg}$ & $\begin{array}{l}\text { Carbonmonoxy haemoglobin from } \\
\text { the fish Leiostomus xanthurus }\end{array}$ \\
\hline $1 \operatorname{cg} 5$ & $\begin{array}{l}\text { Deoxy haemoglobin from } \\
\text { the fish D. akajei }\end{array}$ \\
\hline
\end{tabular}

and the best search model in order to confirm the space group.

\section{Results and discussion}

Crystals of LaHb-IV suitable for X-ray diffraction experiments have average dimensions of about $0.3 \times 0.4 \times 1.0 \mathrm{~mm}$. Assuming the asymmetric unit content to be one tetramer of molecular weight $65 \mathrm{kDa}$, the $V_{\mathrm{M}}$ value is $2.41 \AA^{3} \mathrm{Da}^{-1}$ (Matthews, 1968). Assuming a value of $0.74 \mathrm{~cm}^{3} \mathrm{~g}^{-1}$ for the protein partial specific volume, the calculated solvent content in the crystal is $49 \%$ and the calculated crystal density $1.18 \mathrm{~g} \mathrm{~cm}^{-3}$. The intensities $h 00,0 k 0$ and $00 l$ were collected; however, they all have intensities bellow $1 \sigma(I)$, which indicates the presence of three screw axes. A total of

Table 2

Detailed X-ray diffraction statistics for synchrotron data from a crystal of LaHb-IV.

\begin{tabular}{llrlll}
\hline $\begin{array}{l}\text { Resolution } \\
\text { range }(\AA)\end{array}$ & $\begin{array}{l}\text { No. of } \\
\text { independent } \\
\text { reflections }\end{array}$ & $I / \sigma(I)$ & $\begin{array}{l}R_{\text {merge }}(\%) \\
\text { (\%) }\end{array}$ & $\begin{array}{l}\text { Redun- } \\
\text { dancy }\end{array}$ & $\begin{array}{l}\text { Complete- } \\
\text { ness }(\%)\end{array}$ \\
\hline $20.00-5.87$ & 1581 & 19.92 & 5.8 & 3.17 & 86.3 \\
$5.87-4.68$ & 1665 & 20.01 & 6.5 & 3.24 & 95.9 \\
$4.68-4.09$ & 1670 & 20.49 & 7.2 & 3.24 & 97.4 \\
$4.09-3.72$ & 1652 & 19.34 & 7.8 & 3.25 & 97.8 \\
$3.72-3.46$ & 1662 & 17.24 & 8.5 & 3.24 & 98.5 \\
$3.46-3.25$ & 1657 & 15.11 & 9.6 & 3.24 & 98.7 \\
$3.25-3.09$ & 1661 & 12.45 & 11.2 & 3.24 & 99.6 \\
$3.09-2.96$ & 1666 & 10.59 & 12.5 & 3.23 & 98.7 \\
$2.96-2.84$ & 1639 & 9.59 & 13.5 & 3.24 & 98.0 \\
$2.84-2.75$ & 1629 & 8.42 & 15.1 & 3.26 & 98.6 \\
$2.75-2.66$ & 1646 & 6.49 & 17.8 & 3.23 & 99.0 \\
$2.66-2.58$ & 1620 & 6.10 & 18.9 & 3.27 & 97.1 \\
$2.58-2.52$ & 1642 & 5.33 & 21.3 & 3.22 & 99.8 \\
$2.52-2.46$ & 1606 & 5.12 & 22.7 & 3.27 & 96.3 \\
$2.46-2.40$ & 1622 & 4.56 & 24.2 & 3.24 & 99.6 \\
All reflections & 24618 & 15.17 & 8.8 & 3.24 & 97.3 \\
\hline
\end{tabular}

$\dagger R_{\text {merge }}=100 \times \sum_{h k l}\left[\sum_{i}\left(\left|I_{h k l, i}-\left\langle I_{h k l}\right\rangle\right|\right)\right] / \sum_{h k l, i}\left(I_{h k l}\right)$, where $I_{h k l, i}$ is the intensity of an individual measurement of the reflection with indices $h, k$ and $l$, and $\left\langle I_{h k l}\right\rangle$ is the mean intensity of that reflection. 

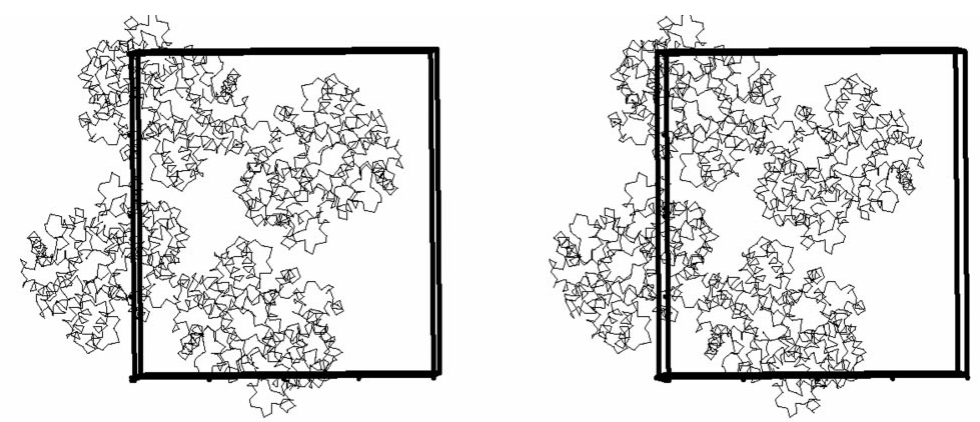

Figure 1

Stereo diagram of the crystal packing of haemoglobin IV from L. anisitsi.

78791 observations having $I>1.0 \sigma(I)$ were collected of 24618 unique reflections. The $\mathrm{X}$-ray diffraction statistics are summarized in Table 2.

The correlation coefficients after translation-function computation using the nine different search models range from 23.2 (22.3) to 62.7 (36.3)\% and the $R_{\text {factor }}$ values range from $39.0(51.5)$ to $54.5(53.9) \%$. The values in parentheses are for the second peaks. The search model which presented the best correlation coefficient and $R_{\text {factor }}$ was for trout haemoglobin (PDB code 1ouu; Tame et al., 1996). The highest magnitude of the correlation function was obtained for the Euler angles $\alpha=97.53, \beta=59.75, \gamma=63.02^{\circ}$ for the first dimer $\left(\alpha_{1} \beta_{1}\right)$ and $\alpha=79.25$, $\beta=8.31, \gamma=24.71^{\circ}$ for the second dimer $\left(\alpha_{2} \beta_{2}\right)$. The fractional coordinates are $T_{x}=0.3072, T_{y}=0.0129, T_{z}=0.4158$ for the first dimer and $T_{x}=0.8661, T_{y}=0.6949$, $T_{z}=0.7090$ for the second dimer.

Translation functions for space groups $P 222, \quad P 222_{1}$ and $P 2_{1} 2_{1} 2$ have been computed using the coordinates of model 1ouu as a search model. The correlation coefficients after translation-function computation for the three space groups range from 32.1 to $37.9 \%$ and the $R_{\text {factor }}$ values range from 49.7 to $51.6 \%$ and strongly indicate that the correct space group is $P 2_{1} 2_{1} 2_{1}$.

Fig. 1 presents the crystal packing for the partially refined structure of the LaHb-IV. The amino-acid sequence will be determined by automated Edman degradation. Further refinement using slow-cooling protocols will be performed using the program $X$-PLOR (Brünger, 1992). The refined model of the LaHb-IV will be used for detailed comparison with other fish haemoglobins.

The authors thank Mr J. R. Brandão Neto and Dr I. Polikarpov (LNLS) for their help in the synchrotron data collection. We also wish to thank Dr Francisco Langeani Neto and Waldener Garutti from the Department of Zoology-IBILCE-UNESP and representatives of the Centro de Aqüicultura from the State University of São Paulo (CAUNESP-UNESP) for their help concerning specimens and technical advice. This work was supported by grants from FAPESP, CNPq, Fundo Bunka (Banco Sumitomo) and FUNDUNESP (Brazil).

\section{References}

Abola, E. E., Prilusky, J. \& Manning, N. O. (1997). Methods Enzymol. 277, 556-71.

Brittain, T. (1987). Comput. Biochem. Physiol. B, 86, 473-481.
Brünger, A. T. (1992). X-PLOR Version 3.1: A System for Crystallography and NMR. Yale University Press, New Haven.

Camardella, L., Caruso, C., D'Avino, R., di Prisco, G., Rutigliano, B., Tamburrini, M., Fermi, G. \& Perutz, M. F. (1992). J. Mol. Biol. 224, 449-460.

De Young, A., Kwiatkowski, L. D. \& Noble, R. W. (1994). Methods Enzymol. 231, 124-150.

Fadel, V., Honda, R. T., Dellamano, M., Smarra, A. L. S., Delatorre, P., Olivieri, J. R., BonillaRodriguez, G. O. \& de Azevedo, W. F. Jr (2000). Acta Cryst. D56, 366-367.

Honda, R. T., Delatorre, P., Fadel, V., Canduri, F., Dellamano, M., de Azevedo, W. F. Jr \& BonillaRodriguez, G. O. (2000). Acta Cryst. D56, $1685-$ 1687.

Jancarik, J. \& Kim, S.-H. (1991). J. Appl. Cryst. 24, 409-411.

Matthews, B. W. (1968). J. Mol. Biol. 33, 491497.

Mazzarella, L., D'Aavino, R., di Prisco, G., Savino, C., Vitagliano, L., Moody, P. C. \& Zagari, A. (1999). J. Mol. Biol. 287, 897-906.

Mylvaganam, S. E., Bonaventura, C., Bonaventura, J. \& Getzoff, E. D. (1996). Nature Struct. Biol. 3, 275-283.

Navaza, J. (1994). Acta Cryst. A50, 157-163.

Otwinowski, Z. (1993). Proceedings of the CCP4 Study Weekend. Data Collection and Processing, edited by L. Sawyer, N. Isaacs \& S. Bailey, pp. 56-62. Warrington: Daresbury Laboratory.

Perutz, M. F. (1996). Nature Struct. Biol. 3, 211212.

Polikarpov, I., Oliva, G., Castellano, E. E., Garratt, R., Arruda, P., Leite, A. \& Craievich, A. (1998). Nucl. Instrum. Methods A, 405, 159-164.

Polikarpov, I., Perles, L. A., de Oliveira, R. T., Oliva, G., Castellano, E. E., Garratt, R. \& Craievich, A. (1998). J. Synchrotron Rad. 5, 7276.

Seixas, F. A., de Azevedo, W. F. Jr \& Colombo, M. F. (1999). Acta Cryst. D55, 1914-1916.

Smarra, A. L. S., Arni, R. K., de Azevedo, W. F. Jr, Colombo, M. \& Bonilla-Rodriguez, G. O. (1997). Protein Pept. Lett. 4, 349-354.

Smarra, A. L. S., de Azevedo, W. F. Jr, Fadel, V., Delatorre, P., Dellamano, M., Colombo, M. F. \& Bonilla-Rodriguez, G. O. (2000). Acta Cryst. D56, 495-497.

Smarra, A. L. S., Fadel, V., Dellamano, M., Olivieri, J. R., de Azevedo, W. F. Jr \& BonillaRodriguez, G. O. (1999). Acta Cryst. D55, 16181619.

Tame, J. R., Wilson, J. C. \& Weber, R. E. (1996). J. Mol. Biol. 259, 749-760. 